\title{
Thalidomide decreases high glucose-induced extracellular matrix protein synthesis in mesangial cells via the AMPK pathway
}

\author{
HONG-XIA ZHANG ${ }^{1 *}$, JIE YUAN $^{2 *}$, YA-FENG LI $^{1}$ and RONG-SHAN LI ${ }^{1}$ \\ Departments of ${ }^{1}$ Nephrology and ${ }^{2}$ Radiology, The Affiliated People's Hospital of Shanxi Medical University, \\ Shanxi Provincial People's Hospital, Taiyuan, Shanxi 030012, P.R. China
}

Received May 4, 2018; Accepted October 26, 2018

DOI: $10.3892 /$ etm.2018.6995

\begin{abstract}
A previous study demonstrated the renal-protective effect of thalidomide (Thd) in diabetic nephropathy rats through the activation of the adenosine monophosphate-activated protein kinase (AMPK) and inhibition of the nuclear factor $\kappa \mathrm{B}$ $(\mathrm{NF}-\kappa \mathrm{B}) /$ monocyte chemoattractant protein-1 (MCP-1) and transforming growth factor (TGF)- $\beta 1$ /mothers against decapentaplegic homolog signaling pathways. The association between AMPK inactivation and high glucose (HG)-induced meningeal cell (MC) proliferation and extracellular matrix (ECM) accumulation via NF- $\mathrm{KB}$ and TGF- $\beta 1$ signaling remains unknown. The aim of the current study was to demonstrate the effects of Thd on cell proliferation and ECM expression in HG-cultured MCs and the underlying mechanisms. HG-cultured human MCs were treated with Thd. Cell proliferation was measured by MTT assay and quantification of cell proliferation was based on the measurement of bromodeoxyuridine incorporation. The differences in TGF- $\beta 1$, fibronectin and MCP-1 protein expression levels were detected via ELISA and western blot analysis. The AMPK signaling pathway was also examined by western blot analysis in MCs. Compound C, an AMPK inhibitor and AICAR (5-aminoimidazole-4-carboxamide $1 \beta$-D-ribofuranoside), an AMPK agonist, were used to analyze the functional role of AMPK in MCs. Cell proliferation was significantly decreased in HG-cultured MCs following treatment with high concentrations of Thd (100 and $200 \mu \mathrm{g} / \mathrm{ml})$ for $24 \mathrm{~h}$ compared with the HG-cultured MC group. Thd suppressed the inflammatory processes in HG-induced MCs. These effects were partially mediated through the activation of AMPK and inhibition of the NF- $\mathrm{kB} / \mathrm{MCP}-1$ signaling pathways. Taken together, these
\end{abstract}

Correspondence to: Dr Rong-Shan Li, Department of Nephrology, The Affiliated People's Hospital of Shanxi Medical University, Shanxi Provincial People's Hospital, 29 Shuangta Road, Taiyuan, Shanxi 030012, P.R. China

E-mail: rongshanli13@163.com

*Contributed equally

Key words: diabetic nephropathy, thalidomide, cell proliferation, adenosine monophosphate-activated protein kinase, nuclear factor $\kappa \mathrm{B}$ results suggest that Thd may have therapeutic potential in diabetic renal injury via the AMPK signaling pathway.

\section{Introduction}

Diabetic nephropathy (DN) is one of the main causes of end-stage renal disease worldwide (1) Typical morphlogical changes of DN include proliferation of mesangial cells (MCs) and accumulation of the extracellular matrix (ECM), which contributes to the thickening of basement membranes and glomerulosclerosis $(2,3)$. It is therefore important to develop effective therapeutic approaches for the treatment and prevention of glomerulosclerosis in diabetes, which may include inhibition of MC proliferation and ECM accumulation.

Hyperglycemia and inflammation serve roles in the initiation of DN (4). Inflammation and pro-inflammatory cytokines are critical to the pathogenesis of DN (5). Nuclear factor $\kappa \mathrm{B}(\mathrm{NF}-\kappa \mathrm{B})$ is considered to be a major signaling pathway associated with inflammation, regulating several inflammatory response genes including monocyte chemoattractant protein-1 (MCP-1) and transforming growth factor (TGF) $\beta 1$ (5). MCP-1 and TGF- $\beta 1$ are secreted by glomerular MCs and are inflammatory mediators in DN $(5,6)$. MCP-1, TGF- $\beta 1$ and fibronectin (FN) secretion can be enhanced via NF- $\kappa \mathrm{B}$ activation, leading to MC proliferation, abnormal ECM accumulation and tubulointerstitial sclerosis $(7,8)$.

Adenosine monophosphate-activated protein kinase (AMPK) is an enzyme associated with cellular energy homeostasis (9). Exposure to high glucose (HG) concentrations suppresses AMPK activation (10-14), inhibiting the activation of NF- $\kappa \mathrm{B}$ (15). In addition, inactivation of AMPK is associated with pro-inflammatory and pro-fibrotic damage (16).

Thalidomide (Thd) was previously withdrawn from the market due to the high incidence of teratogenicity (17). However, the return of Thd in clinical practice is primarily due to its anti-inflammatory, anti-fibrotic and immune-modulatory properties, as it is currently used for the treatment of inflammatory bowel disease, multiple myeloma and rheumatic disease (17). Thd can suppress the levels of pro-inflammatory cytokines, which include tumor necrosis factor $\alpha$, interleukin (IL)-1 $\beta$, IL-6 and TGF- $\beta 1$ (17-19). Previous studies have demonstrated the anti-inflammatory effects of Thd in diabetic retinopathy, neuropathy and cardiomyopathy animal models (20-22). A previous study demonstrated the renal-protective effect of Thd 
in $\mathrm{DN}$ rats through the activation of $\mathrm{AMPK}$ and inhibition of NF- $\mathrm{B} / \mathrm{MCP}-1$ and TGF- $\beta 1 /$ mothers against decapentaplegic homolog (Smad) signaling pathways (23). The association between Thd-induced AMPK activation and the inhibition of HG-induced MC proliferation and ECM accumulation via $N F-\kappa B$ and TGF- $\beta 1$ signaling remains unknown. The aim of the present study was to demonstrate the effects of Thd on cell proliferation and ECM expression in HG-cultured MCs and the underlying mechanisms.

\section{Materials and methods}

Cell culture. Human mesangial cell line T-SV40 was donated by Dr Li Xuewang at Union Medical College Hospital (Beijing, China). Cells were cultured in Dulbecco's modified Eagle's media (DMEM; HyClone; GE Healthcare Life Sciences, Logan, UT, USA) supplemented with $10 \%$ fetal bovine serum (FBS; HyClone; GE Healthcare Life Sciences) and maintained at $37^{\circ} \mathrm{C}$ in a $5 \% \mathrm{CO}_{2}$-humidified incubator. Medium was changed every 2 days and only cells at passage 3-5 were subsequently used. Cells were synchronized prior to use in subsequent experiments following pre-incubation with Minimum Essential Medium (MEM; HyClone; GE Healthcare Life Sciences) supplemented with $1 \%$ FBS at $37^{\circ} \mathrm{C}$ overnight. Cells were subsequently exposed to Normal glucose $(\mathrm{NG})$ containing $5.6 \mathrm{mmol} / \mathrm{l} \mathrm{D}$-glucose and $\mathrm{HG}$ containing $30 \mathrm{mmol} / \mathrm{l} \mathrm{D}$-glucose with additional administration of Thd $(0,10,50,100$ and $200 \mu \mathrm{g} / \mathrm{ml})$ at $37^{\circ} \mathrm{C}$ for 12,24 or $48 \mathrm{~h}$.

Reagents. Thd (Sigma-Aldrich; Merck KGaA, Darmstadt, Germany) was dissolved in dimethylsulfoxide (DMSO; Sigma-Aldrich) and diluted in saline to a final concentration of $100 \mathrm{mg} / \mathrm{ml}$ stock solution. In the Thd-treated groups, the Thd stock solution was diluted in DMSO to a final concentration of $0.2 \%$. The control groups received the corresponding volume of vehicle control (DMSO only). AMPK inhibitor (compound C) was purchased from Merck KGaA and AMPK agonist (5-aminoimidazole-4-carboxamide $1 \beta$-D-ribofuranoside; AICAR) was purchased from Cell Signaling Technology, Inc. (Danvers, MA, USA). For compound $\mathrm{C}(\mathrm{C})$ or AICAR (A) treatment, synchronized MCs were treated with or without $10 \mu \mathrm{M} \mathrm{C}$ or $1 \mathrm{mM}$ A under NG at $37^{\circ} \mathrm{C}$ for $1 \mathrm{~h}$. Following inhibitor or activator incubation, cells were treated under HG with or without Thd $(100 \mu \mathrm{g} / \mathrm{ml})$ at $37^{\circ} \mathrm{C}$ for $24 \mathrm{~h}$.

MTT assay. Cell proliferation was measured by MTT assay. Following 12, 24 or 48-h treatment with various concentrations $(0,10,50,100$ and $200 \mu \mathrm{g} / \mathrm{ml})$ of Thd, MCs were seeded into 96 -well plates at a density of $5 \times 10^{3}$ cells/well. Following incubation, $20 \mu \mathrm{l} \mathrm{MTT}(5 \mathrm{mg} / \mathrm{ml}$; Invitrogen; Thermo Fisher Scientific, Inc., Waltham, MA, USA) was added to each well and further incubated at $37^{\circ} \mathrm{C}$ for $4 \mathrm{~h}$. Following incubation, the medium was removed and $150 \mu 1 \mathrm{DMSO}$ was added to each sample. Cell proliferation was determined by measuring the absorbance at $560 \mathrm{~nm}$ using a microplate reader (Model 550; Bio-Rad Laboratories, Inc., Hercules, CA, USA). The mean optical density was determined by examining seven wells per group.
Bromodeoxyuridine (BrdU) assay. The quantification of $\mathrm{MC}$ proliferation was based on the measurement of BrdU incorporation during DNA synthesis. Following 12, 24 or 48-h treatment with various concentrations $(0,10,50,100$ and $200 \mu \mathrm{g} / \mathrm{ml})$ of Thd, MCs were seeded into 96-well plates, as described above. The cells were subsequently treated with BrdU during the final $2 \mathrm{~h}$ of incubation. The BrdU Cell Proliferation assay kit (cat. no. 2750; EMD Millipore, Billerica, MA, USA) was performed according to the manufacturer's protocol.

ELISA. Cell supernatant was harvested from the NG group and different treatment groups under $\mathrm{HG}$ with Thd $(0,10,50,100$ and $200 \mu \mathrm{g} / \mathrm{ml}$ ) and centrifuged at $1,500 \mathrm{x} \mathrm{g}$ for $10 \mathrm{~min}$ at $4^{\circ} \mathrm{C}$. The level of TGF- $\beta 1$ (cat. no. EK0513), MCP-1 (cat. no. EK0441) and FN (cat. no. EK0349) secreted were detected using ELISA kits (all Boster Biological Engineering Co., Wuhan, China) (24). Absorbance was measured at $450 \mathrm{~nm}$ using a microplate reader (Model 550; Bio-Rad Laboratories, Inc.). Each sample was analyzed in triplicate.

Western blot analysis. MCs were washed with PBS. Total protein was extracted from MCs using radioimmunoprecipitation assay buffer (Beyotime Institute of Biotechnology, Haimen, China) supplemented with protease (cat. no. HY-K0011) and phosphatase inhibitors (cat. no. HY-K0021; each MedChemExpress, Monmouth Junction, NJ, USA), which were added prior to use. Total protein was quantified using a bicinchoninic acid assay (BeyotimeInstitute of Biotechnology) and 50 $\mu$ g protein/lane was separated via SDS-PAGE on a $12 \%$ gel. The separated proteins were subsequently transferred onto nitrocellulose membranes (Whatman International Ltd., Maidstone, Kent, UK) and blocked using blocking buffer (PBS and 0.1\% Tween-20) with $5 \%$ non-fat milk for $1 \mathrm{~h}$ at room temperature. Then membranes were incubated with primary antibodies against TGF- $\beta 1$ (1:1,000; cat. no. ab92486), MCP-1 (1:1,000; cat. no. ab9669),

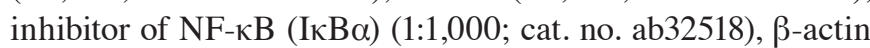
(1:1,000; cat. no. ab8226; all Abcam, Cambridge, UK), NF-кB (1:1,000; cat. no. 4764), AMPK (1:1,000; cat. no. 2532), phosphorylated AMPK (p-AMPK; 1:1,000; cat. no. 50081), tubulin (1:1,000; cat. no. 2148) and GAPDH (1:1,000; cat. no. 5174; all Cell Signaling Technology, Inc.) overnight at $4^{\circ} \mathrm{C}$. Membranes were washed three times with Tris-buffered saline containing Tween ${ }^{\circledR}-20$. Membranes were incubated with corresponding horseradish peroxidase-conjugated anti-rabbit immunoglobulin G (IgG; 1:5,000; cat. no. sc2370) or anti-mouse IgG (1:2,000; cat. no. sc2380) secondary antibodies (each, Santa Cruz Biotechnology, Inc., Dallas, TX, USA) for $90 \mathrm{~min}$ at room temperature. The membranes were then reacted with an ECL-plus chemiluminescent detection HRP reagent (Beyotime Institute of Biotechnology). Protein expression was quantified using the Quantity One analysis system (version 4.62; Bio-Rad Laboratories, Inc.).

Statistical analysis. Data are presented as the mean \pm standard error of the mean. All statistical analyses were performed using SPSS software (version 19.0; IBM Corp., Armonk, NY, USA). Differences between groups were measured using a one-way analysis of variance followed by a post hoc Bonferroni correction test. $\mathrm{P}<0.05$ was considered to indicate a statistically significant difference. 

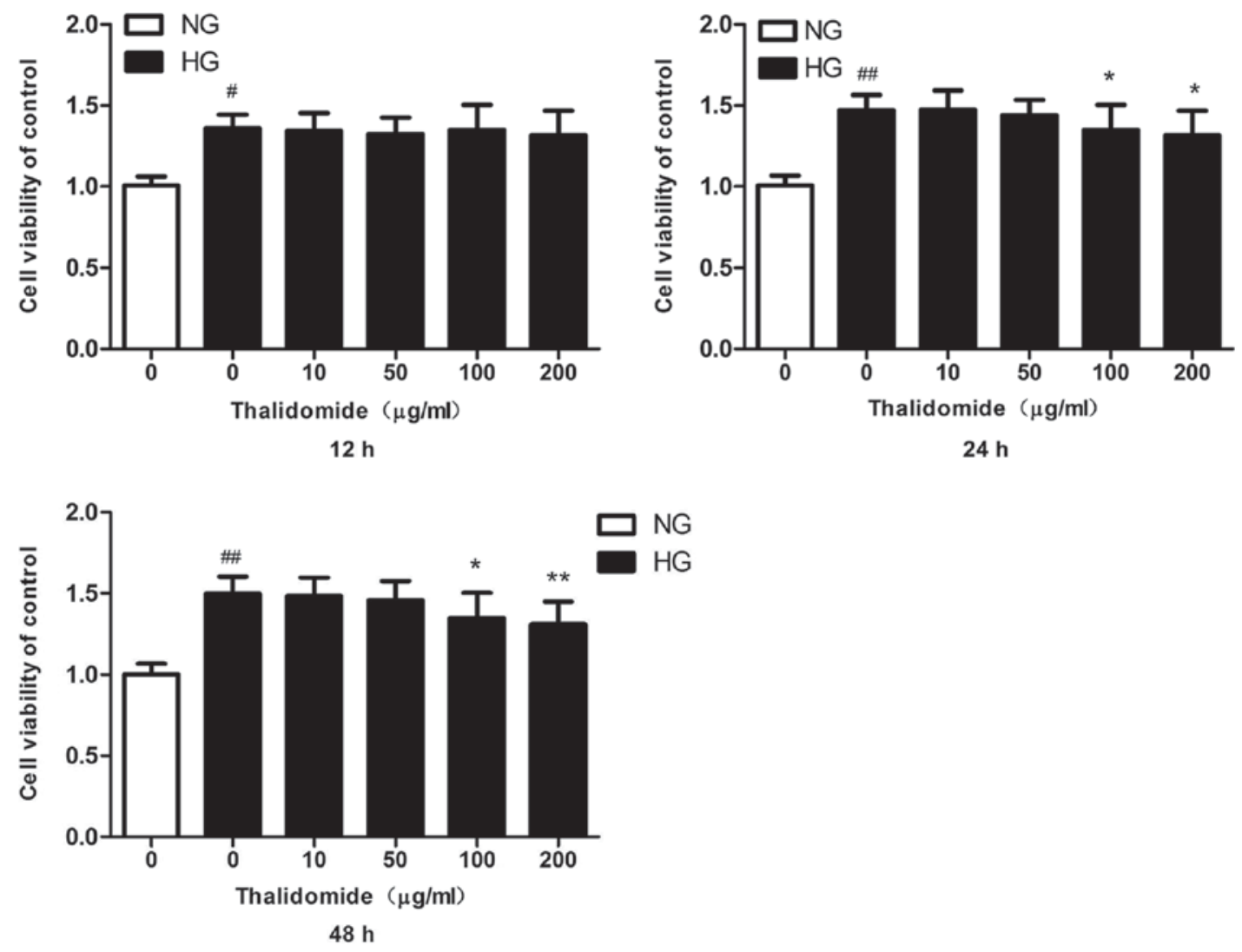

Figure 1. Effects of Thd on HG-induced MC viability by MTT assay. NG-cultured MCs were grown in DMEM containing 5.6 mmol/1 D-glucose, whilst HG-cultured MCs were grown in Dulbecco's modified Eagle's medium containing $30 \mathrm{mmol} / 1 \mathrm{D}$-glucose and following treatment with various concentrations $(0,10,50,100$ and $200 \mu \mathrm{g} / \mathrm{ml})$ of Thd for 12,24 or $48 \mathrm{~h}$ the MTT assay was used to measure cell viability. Data are presented as the mean \pm standard error of the mean $(\mathrm{n}=5)$. ${ }^{\#} \mathrm{P}<0.01$ and ${ }^{\# \#} \mathrm{P}<0.001$ vs. NG group; ${ }^{*} \mathrm{P}<0.01$ and ${ }^{* *} \mathrm{P}<0.001$ vs. HG group. Thd, thalidomide; HG, high glucose; MC, mesangial cell; NG, normal glucose.

\section{Results}

In vitro dosage of Thd in human MCs. To determine the in vitro dosage of Thd in MCs, cell viability was measured by MTT assay. The MTT assay was performed following treatment with various concentrations $(0,10,50,100$ and $200 \mu \mathrm{g} / \mathrm{ml})$ of Thd for 12, 24 or $48 \mathrm{~h}$. Cell viability significantly increased in HG-cultured MCs compared with NG-cultured MCs for 12, 24 and $48 \mathrm{~h}$ (Fig. 1). Cell viability significantly decreased in HG-cultured MCs following treatment with Thd 100 and $200 \mu \mathrm{g} / \mathrm{ml}$ for $24 \mathrm{~h}$ compared with the HG-cultured MC group. In addition, similar results were observed in HG-cultured MCs following treatment with Thd for $48 \mathrm{~h}$. There was no significant cytotoxic effect observed in HG-induced MCs following treatment with Thd for $12 \mathrm{~h}$.

BrdU assays were performed to examine the effects of Thd on MC cell proliferation. BrdU incorporation significantly increased in HG-cultured MCs compared with NG-cultured MCs for 12, 24 and $48 \mathrm{~h}$ (Fig. 2). In addition, BrdU incorporation significantly decreased in HG-cultured MCs following treatment with Thd $100 \mu \mathrm{g} / \mathrm{ml}$ for $24 \mathrm{~h}$ compared with the HG-cultured MC group. Therefore, treatment with Thd $100 \mu \mathrm{g} / \mathrm{ml}$ for $24 \mathrm{~h}$ in HG-cultured MCs was used in all subsequent experiments.

Effect of Thd on TGF- $\beta 1, F N$ and MCP-1 expression. The expression levels of TGF- $\beta 1, \mathrm{FN}$ and MCP-1 were analyzed in MCs by ELISA. The protein expression levels of TGF- $\beta 1$,
FN and MCP-1 were significantly enhanced in HG-cultured MCs compared with NG-cultured MCs (Fig. 3). However, the expression levels significantly decreased in HG-cultured MCs following treatment with high concentrations of Thd (100 and $200 \mu \mathrm{g} / \mathrm{ml}$ ) compared with the HG-cultured MC group.

Thd modulates the expression of $N F-\kappa B, I \kappa B \alpha, M C P-1$ and $T G F-\beta 1$ in HG-induced MCs. To investigate the potential involvement of the NF- $\mathrm{KB} / \mathrm{MCP}-1$ signaling pathways in the regulation of HG-induced cell proliferation, the protein expression levels of NF- $-\mathrm{B}, \mathrm{I \kappa B} \alpha, \mathrm{MCP}-1$ and TGF- $\beta 1$ were determined by western blot analysis (Fig. 4A). The expression levels of inflammatory cytokines NF-кB, MCP-1 and TGF- $\beta 1$ were significantly increased whereas the expression level of I $\kappa \mathrm{B} \alpha$ was significantly decreased in HG-cultured MCs compared with NG-cultured MCs (Fig. 4B). In addition, treatment with Thd significantly decreased the expression levels of HG-induced inflammatory cytokines NF-кB, MCP-1 and TGF- $\beta 1$ whereas the expression level of IкB $\alpha$ was significantly increased in HG-cultured MCs (Fig. 4B). These results suggest that Thd may exert anti-inflammatory effects on HG-induced MCs.

Thd attenuates HG-induced NF- $\kappa B$ and TGF- $\beta 1$ through AMPK signaling. The protein expression levels of AMPK and p-AMPK were determined by western blot analysis in MCs (Fig. 5A). The expression level of $\mathrm{p}$-AMPK was significantly decreased in HG-cultured MCs compared with NG-cultured MCs (Fig. 5B). 

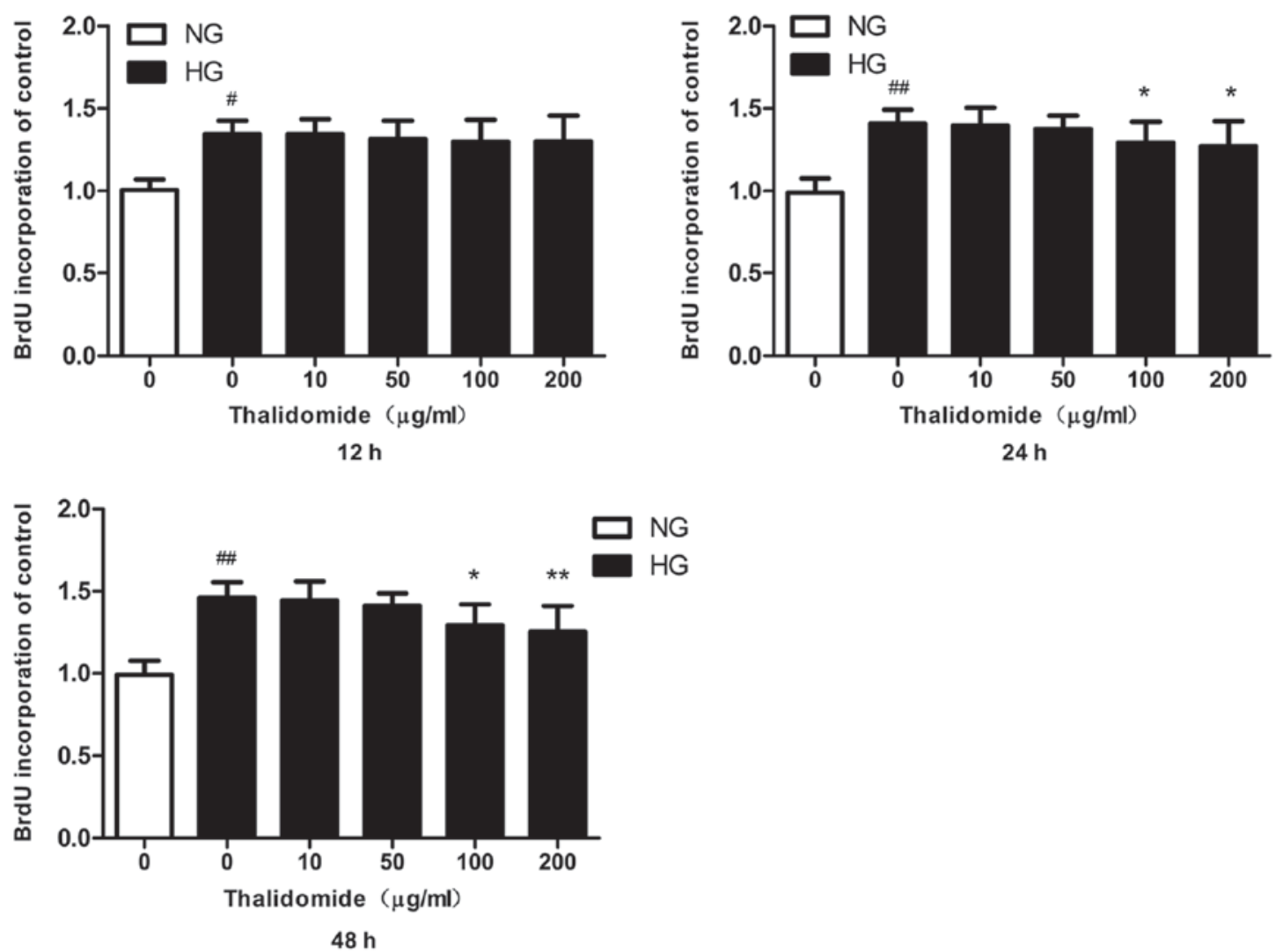

Figure 2. Effects of Thd on HG-induced MC proliferation by BrdU assay. NG-cultured MCs were grown in DMEM containing $5.6 \mathrm{mmol} / 1 \mathrm{D}$-glucose, whilst HG-cultured MCs were grown in DMEM containing $30 \mathrm{mmol} / \mathrm{l}$ D-glucose and following treatment with various concentrations $(0,10,50,100 \mathrm{and} 200 \mu \mathrm{g} / \mathrm{ml})$ of Thd for 12,24 or $48 \mathrm{~h}$ the BrdU assay was used to quantify cell proliferation. Data are presented as the mean \pm standard error of the mean ( $\mathrm{n}=5$ ). ${ }^{\#} \mathrm{P}<0.01$ and ${ }^{\# \#} \mathrm{P}<0.001$ vs. NG group; ${ }^{\mathrm{P}}<0.01$ and ${ }^{* *} \mathrm{P}<0.001$ vs. HG group. Thd, thalidomide; HG, high glucose; MC, mesangial cell; BrdU, bromodeoxyuridine; DMEM, Dulbecco's modified Eagle's medium; NG, normal glucose.
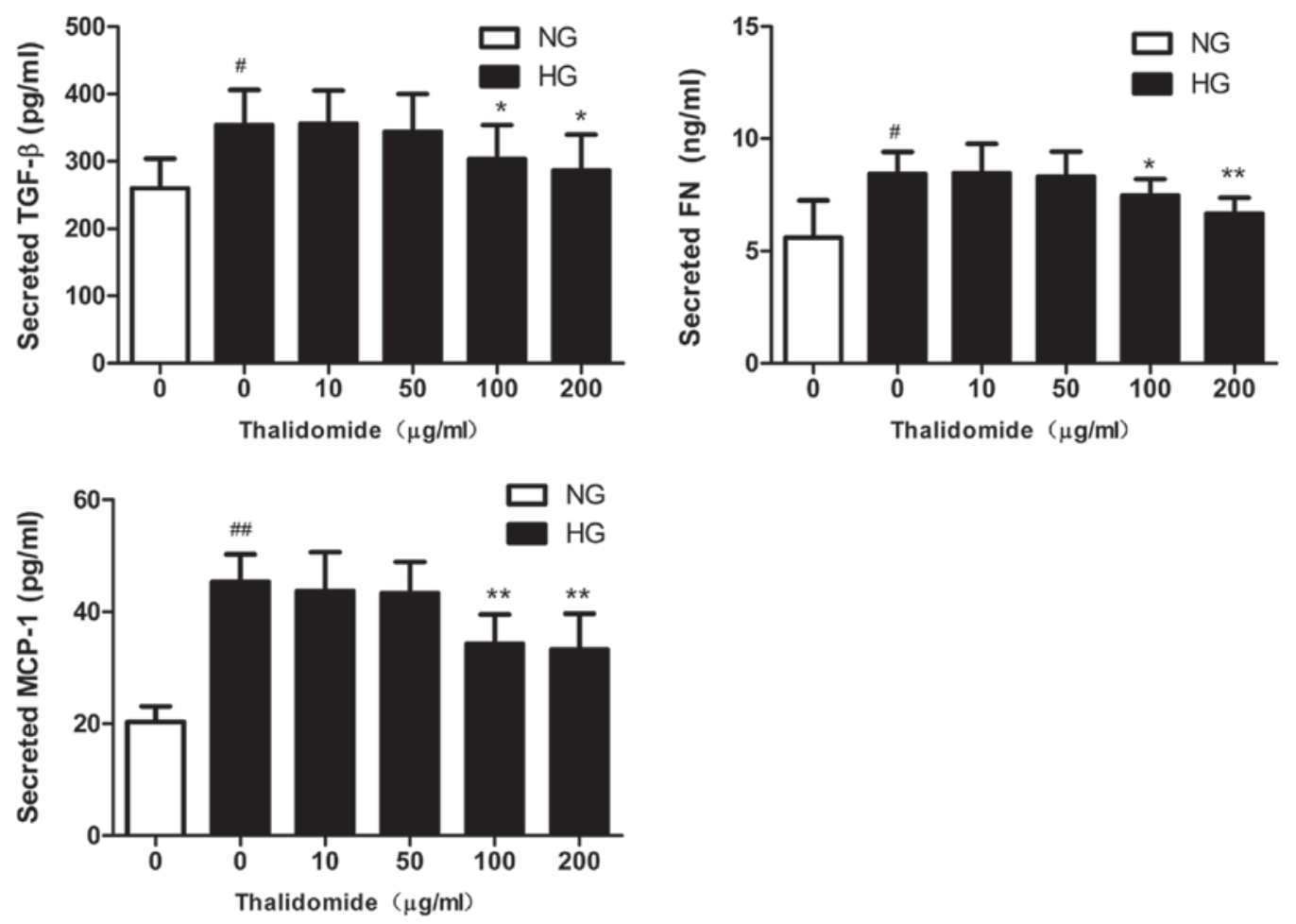

Figure 3. TGF- $\beta 1$, FN and MCP-1 protein expression in MC supernatant. Following treatment with various concentrations $(0,10,50,100 \mathrm{and} 200 \mu \mathrm{g} / \mathrm{ml})$ of Thd for $24 \mathrm{~h}$, the protein expression levels of TGF- $\beta 1, \mathrm{FN}$ and MCP-1 were analyzed by ELISA. Data are presented as the mean \pm standard error of the mean $(\mathrm{n}=3)$. ${ }^{\#} \mathrm{P}<0.01$ and ${ }^{\# \#} \mathrm{P}<0.001$ vs. NG group; ${ }^{*} \mathrm{P}<0.01$ and ${ }^{* *} \mathrm{P}<0.001$ vs. HG group. TGF- $\beta 1$, transforming growth factor $\beta 1 ; \mathrm{FN}$, fibronectin; MCP-1, monocyte chemoattractant protein-1; MC, mesangial cell; Thd, thalidomide; NG, normal glucose; HG, high glucose. 
A

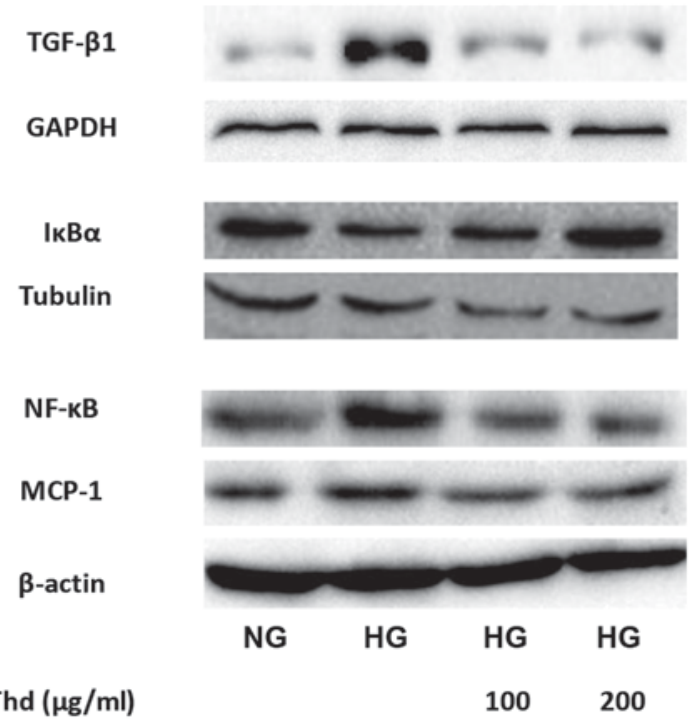

B

44 kDa

$36 \mathrm{kDa}$

35 kDa

$50 \mathrm{kDa}$

$65 \mathrm{kDa}$

$12 \mathrm{kDa}$

$42 \mathrm{kDa}$
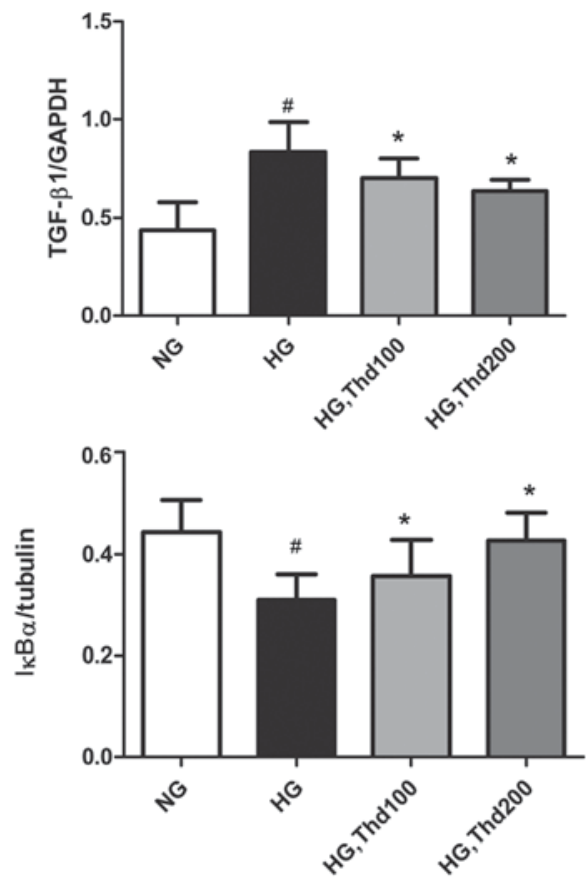
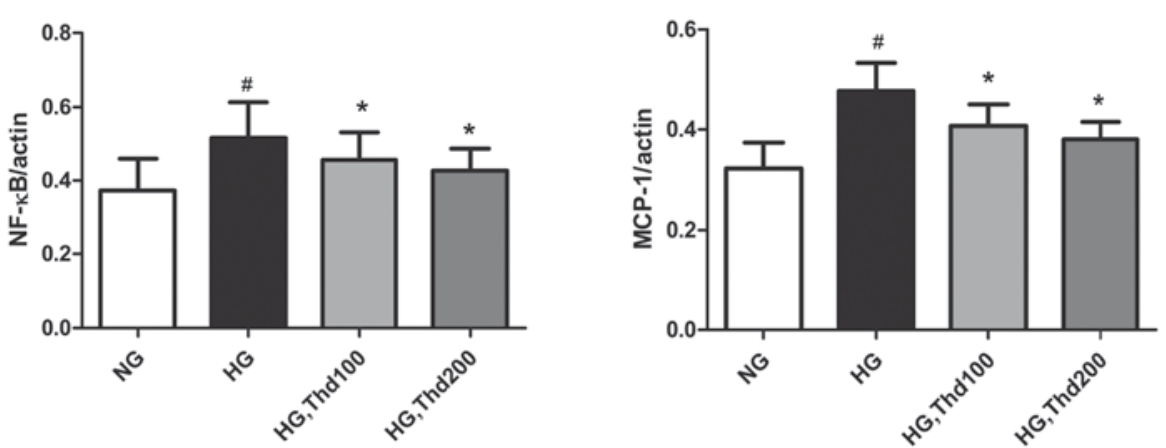

Figure 4. Effects of Thd on NF- $\kappa \mathrm{B}, \mathrm{I} \kappa \mathrm{B} \alpha, \mathrm{MCP}-1$ and TGF- $\beta 1$ expression. (A) The protein expression levels of NF- $\kappa \mathrm{B}$, I $\kappa \mathrm{B} \alpha$, MCP-1 and TGF- $\beta 1$ were determined using western blot analysis in NG-cultured and HG-cultured MCs following treatment with Thd (100 or $200 \mu \mathrm{g} / \mathrm{ml}$ ) for $24 \mathrm{~h}$. (B) Quantification of $\mathrm{NF}-\kappa \mathrm{B}, \mathrm{I} \kappa \mathrm{B} \alpha, \mathrm{MCP}-1$ and TGF- $\beta 1$ protein expression. Data are presented as the mean \pm standard error of the mean ( $\mathrm{n}=4)$. ${ }^{\prime \prime} \mathrm{P}<0.01 \mathrm{vs}$. $\mathrm{NG}$ group and ${ }^{*} \mathrm{P}<0.01$ vs. HG group. Thd, thalidomide; NF- $\kappa$ B, nuclear factor $\kappa \mathrm{B}$; I $\mathrm{KB} \alpha$, inhibitor of NF- $\kappa \mathrm{B}$; MCP-1, monocyte chemoattractant protein- 1 ; TGF- $\beta 1$, transforming growth factor $\beta 1$; MC, mesangial cell; $\mathrm{NG}$, normal glucose; $\mathrm{HG}$, high glucose.

A

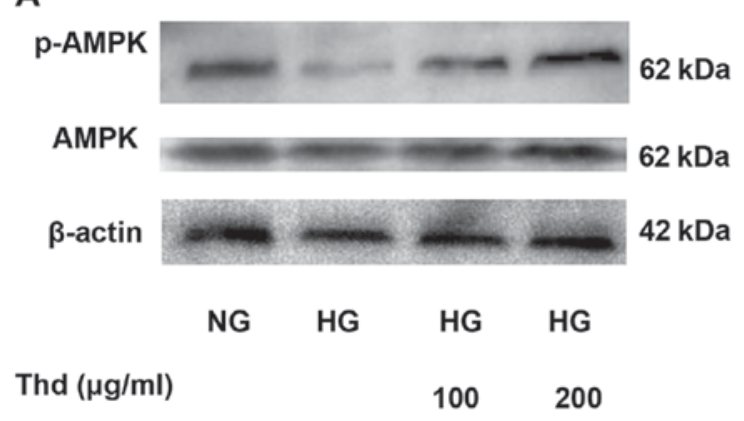

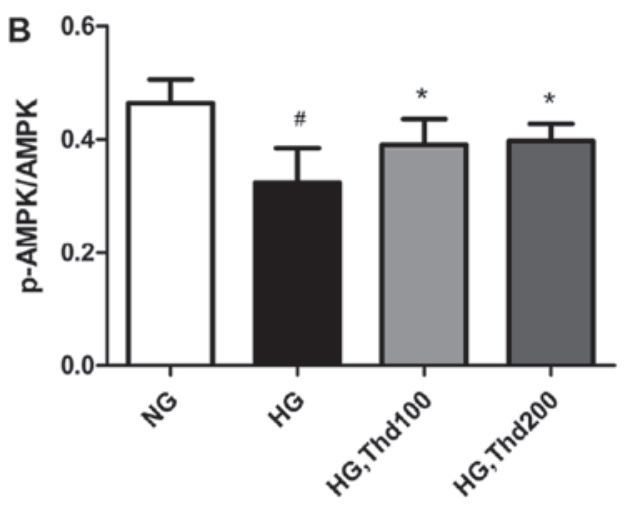

Figure 5. Effects of Thd on AMPK and p-AMPK expression. (A) The protein expression levels of AMPK and p-AMPK were determined using western blot analysis in NG-cultured and HG-cultured MCs following treatment with Thd (100 or $200 \mu \mathrm{g} / \mathrm{ml}$ ) for $24 \mathrm{~h}$. (B) Quantification of p-AMPK/AMPK protein expression. Data are presented as the mean \pm standard error of the mean $(n=4) .{ }^{~} \mathrm{P}<0.01$ vs. NG group and ${ }^{*} \mathrm{P}<0.01$ vs. HG group. Thd, thalidomide; AMPK, AMP-activated protein kinase; p-AMPK, phosphorylated-AMPK; MC, mesangial cell; NG, normal glucose; HG, high glucose.

In addition, treatment with high concentrations of Thd (100 and $200 \mu \mathrm{g} / \mathrm{ml}$ ) significantly increased the expression level of p-AMPK (Thr172) compared with the HG-cultured MC group
(Fig. 5B). Furthermore, treatment with Thd appeared to activate AMPK and inhibit TGF- $\beta 1$ and $N F-\kappa B$ protein expression in a similar manner to AICAR. By contrast, compound $\mathrm{C}$ appeared 
A

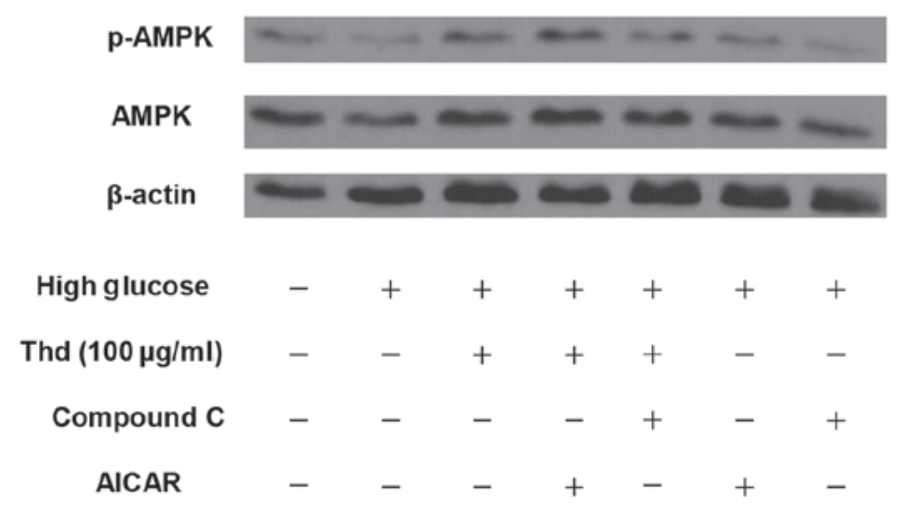

B

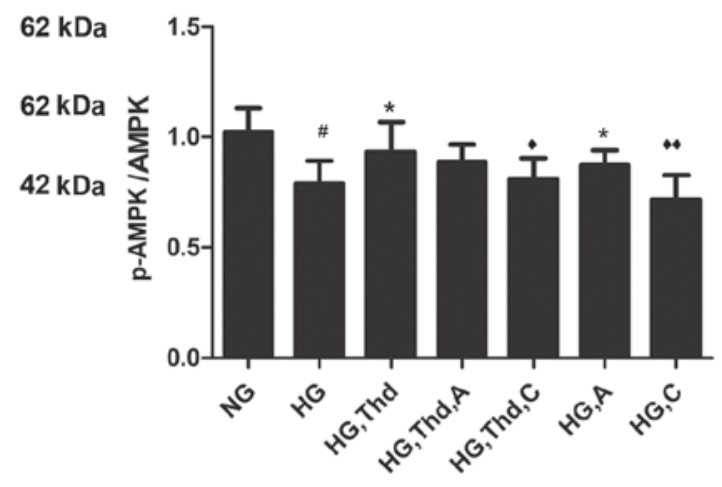

Figure 6. Effects of Thd on AMPK and p-AMPK protein expression in HG-induced MCs with or without compound C and/or AICAR. (A) The protein expression levels of AMPK and p-AMPK were determined using western blot analysis in NG-cultured and HG-cultured MCs following treatment with or without compound $\mathrm{C}(10 \mu \mathrm{M})$ and/or AICAR $(1 \mathrm{mM})$. MCs were treated with or without Thd $(100 \mu \mathrm{g} / \mathrm{ml})$ for $24 \mathrm{~h}$. MCs were treated with compound C or AICAR for $1 \mathrm{~h}$ before prior to modulation. (B) Quantification of $\mathrm{p}$-AMPK/AMPK protein expression. Data are presented as the mean \pm standard error of the mean ( $\mathrm{n}=4$ ). ${ }^{\#} \mathrm{P}<0.01$ vs. NG group; ${ }^{*} \mathrm{P}<0.01$ vs. $\mathrm{HG}$ group; ${ }^{\bullet} \mathrm{P}<0.01$ and ${ }^{\bullet} \mathrm{P}<0.001$ vs. HG+Thd group. Thd, thalidomide; AMPK, AMP-activated protein kinase; $\mathrm{p}-\mathrm{AMPK}$, phosphorylated AMPK; HG, high glucose; A or AICAR, 5-aminoimidazole-4-carboxamide 1 $\beta$-D-ribofuranoside; MC, mesangial cell; C, compound C.

A

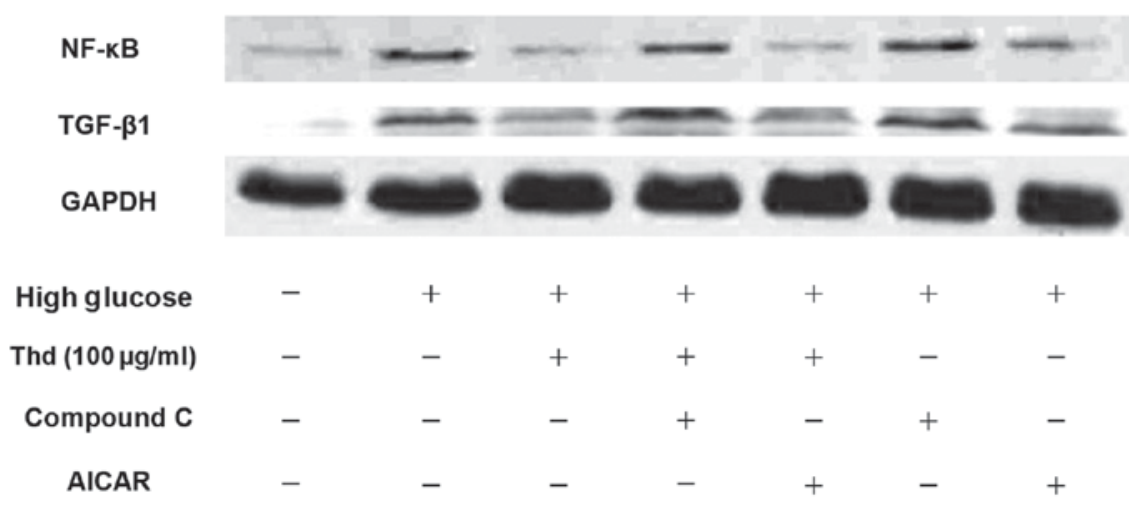

$65 \mathrm{kDa}$

$44 \mathrm{kDa}$

$36 \mathrm{kDa}$

B
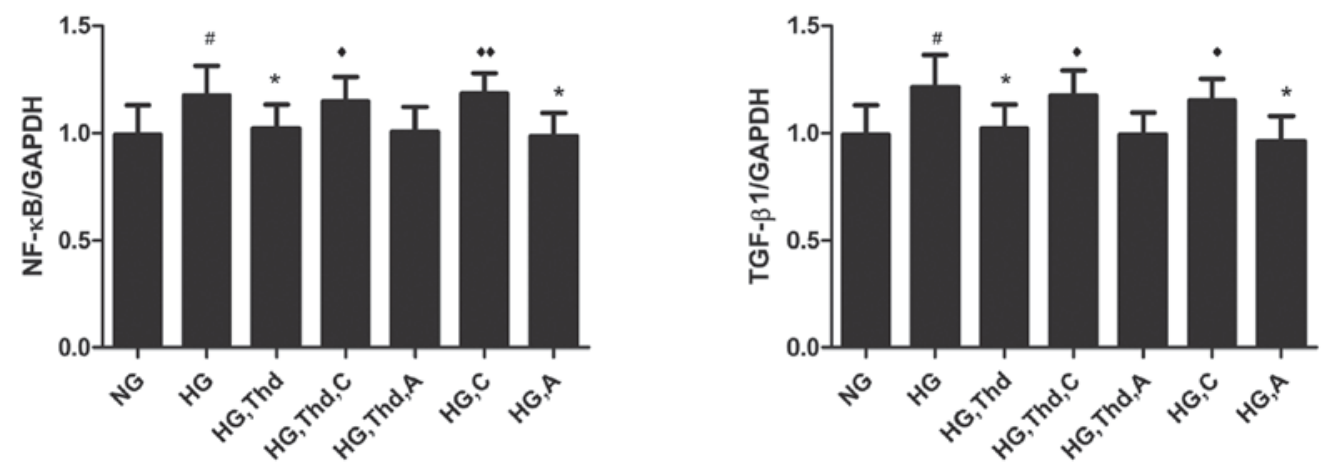

Figure 7. Effects of Thd on NF- $\mathrm{kB}$ and TGF- $\beta 1$ protein expression in HG-induced MCs with or without compound C and AICAR. (A) The protein expression levels of NF- $\mathrm{kB}$ and TGF- $\beta 1$ were determined using western blot analysis in NG-cultured and HG-cultured MCs following treatment with or without compound $\mathrm{C}(10 \mu \mathrm{M})$ and/or AICAR $(1 \mathrm{mM})$. MCs were treated with or without Thd $(100 \mu \mathrm{g} / \mathrm{ml})$ for $24 \mathrm{~h}$. MCs were treated with compound C or AICAR for $1 \mathrm{~h}$ prior to glucose modulation. (B) Quantification of NF- $\mathrm{KB}$ and TGF- $\beta 1$ protein expression. Data are presented as the mean \pm standard error of the mean $(\mathrm{n}=4) .{ }^{*} \mathrm{P}<0.01$ vs. NG group; ${ }^{*} \mathrm{P}<0.01$ vs. HG group; ${ }^{\wedge} \mathrm{P}<0.01$ and ${ }^{*} \mathrm{P}<0.001$ vs. HG+Thd group. Thd, thalidomide; NF- $\kappa B$, nuclear factor $\kappa B$; TGF- $\beta 1$, transforming growth factor $\beta 1$; HG, high glucose; A or AICAR, 5-aminoimidazole-4-carboxamide 1 $\beta$-D-ribofuranoside; MC, mesangial cell; C, compound C.

to reverse Thd-induced AMPK activation and enhance TGF- $\beta 1$ and NF- $\kappa$ B protein expression (Figs. 6 and 7).

Effects of the AMPK signaling pathway on cell viability and the cytotoxic potential of Thd. In order to examine the effects of the AMPK signaling pathway in HG-cultured MCs, cell proliferation was measured by MTT assay. Cell viability was significantly decreased in HG-cultured MCs following treatment with Thd $100 \mu \mathrm{g} / \mathrm{ml}$ compared with the HG-cultured MC group. Similarly, cell viability significantly decreased in 

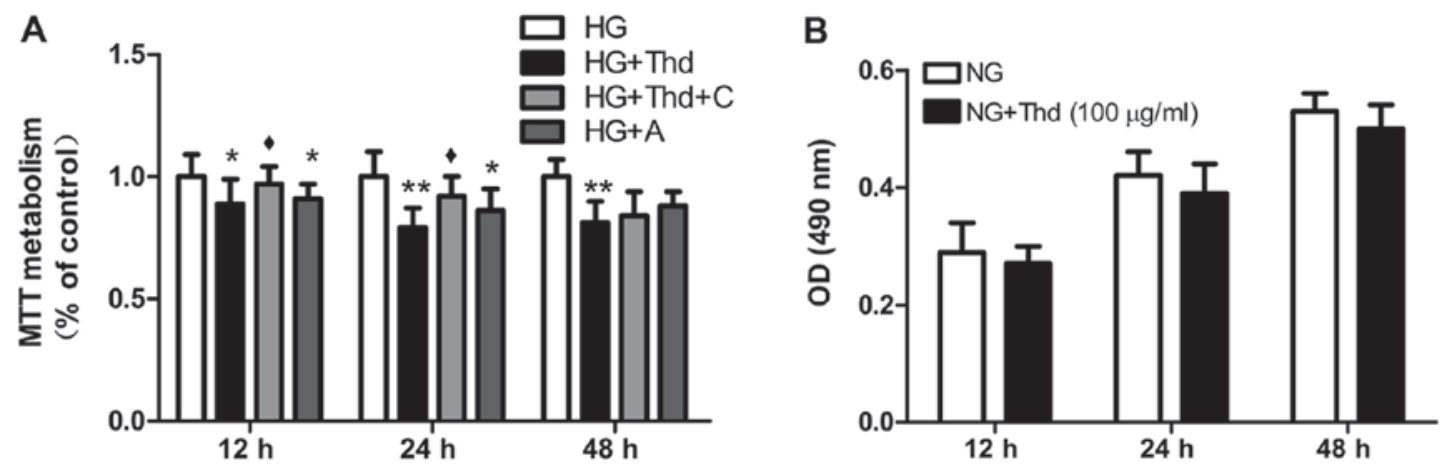

Figure 8. Effects of Thd on MC viability in the presence of compound C and AICAR. (A) MTT assay was used to measure cell viability in HG-induced MCs following treatment with compound $\mathrm{C}(10 \mu \mathrm{M})$ and AICAR $(1 \mathrm{mM})$. (B) MTT assay was used to measure cell viability in NG-cultured MCs following treatment with Thd $(100 \mu \mathrm{g} / \mathrm{ml})$ for 12,24 or $48 \mathrm{~h}$. Values are expressed as mean $\pm \mathrm{SEM}(\mathrm{n}=4)$. ${ }^{*} \mathrm{P}<0.01$ and ${ }^{* *} \mathrm{P}<0.01 \mathrm{vs}$. the HG group; ${ }^{*} \mathrm{P}<0.01 \mathrm{vs}$. the $\mathrm{HG}+\mathrm{Thd}$ group. Thd, thalidomide; MC, mesangial cell; A or AICAR, 5-aminoimidazole-4-carboxamide 1 $\beta$-D-ribofuranoside; HG, high glucose; NG, normal glucose; C, compound C; OD, optical density.

HG-cultured MCs following treatment with AICAR for 12 or $24 \mathrm{~h}$ compared with the HG-cultured MC group. However, the Thd-induced decrease in cell viability was significantly reversed in HG-cultured MCs following treatment with compound $\mathrm{C}$ (Fig. 8A). In addition, there was no significant cytotoxic effect observed in NG-induced MCs following treatment with Thd $(100 \mu \mathrm{g} / \mathrm{ml})$ for 12,24 or $48 \mathrm{~h}$ (Fig. 8B).

\section{Discussion}

The current study is the first to identify the protective effects of Thd against HG-induced matrix protein synthesis in human mesangial cells, to the best of our knowledge. Following 24-h Thd incubation, HG-induced inflammatory cytokines and abnormal ECM protein accumulation were significantly decreased compared with the HG group. These protective effects may be due to the upregulation of p-AMPK and inhibition of the NF- $\mathrm{kB} / \mathrm{MCP}-1$ signaling pathways.

Chronic inflammation serves a role in the initiation of DN $(4,5)$. Several inflammatory cytokines including adhesion molecules and pro-inflammatory cytokines, are thought to be involved in the pathogenesis of DN $(4,25)$. NF- $\kappa B$, a major signaling pathway in inflammation, is activated in response to cellular stress which includes hyperglycemia, obesity and oxidative stress (26). NF- $\kappa \mathrm{B}$ activation induces the transcription of several target genes including MCP-1, TNF- $\alpha$ and the interleukin system (26). MCP-1 can accelerate the recruitment of macrophages to the kidneys following renal injury in DN, whereas TGF- $\beta 1$ upregulation can inhibit the accumulation of ECM in DN (27-29). In the current study, the expression levels of the inflammatory cytokines NF- $\kappa \mathrm{B}$, MCP-1 and TGF- $\beta 1$ significantly increased in HG-induced MCs, and significantly decreased following treatment with Thd. By contrast, treatment with Thd significantly increased the expression level of IкB $\alpha$. These results suggest that Thd may exert anti-inflammatory effects through inhibition of the NF- $\mathrm{KB}$ signaling pathway.

Previous studies have demonstrated that AMPK activation in the diabetic kidney can be inhibited via multiple mechanisms $(30,10,11)$. Studies have revealed that the downregulation of p-AMPK aggravates the abnormal accumulation of ECM proteins and glomerular hypertrophy via activation of the mammalian target of rapamycin and the TGF- $\beta 1 / \mathrm{Smad} 4$ signaling pathway $(30,31)$. AMPK activation serves a role in the downregulation of TGF- $\beta 1$ in DN (32). Previous studies have demonstrated that AMPK activation can inhibit the activation of NF- $\mathrm{KB}(12,13)$. AMPK could therefore be used as a target for the treatment of DN. In the present study, treatment with high concentrations of Thd (100 and $200 \mu \mathrm{g} / \mathrm{ml}$ ) for $24 \mathrm{~h}$ significantly increased the expression level of p-AMPK (Thr172) and significantly decreased the expression levels of inflammatory cytokines NF- $\mathrm{KB}, \mathrm{MCP}-1$ and TGF $\beta$ compared with the HG-cultured MC group. Furthermore, treatment with Thd appeared to activate AMPK and inhibit TGF- $\beta 1$ and NF- $\mathrm{KB}$ protein expression in a similar manner to AICAR. Incubation with compound $\mathrm{C}$ appeared to reverse Thd-induced AMPK activation and enhance NF- $\kappa B$, MCP-1 and TGF- $\beta 1$ protein expression. Taken together, these results suggest that the anti-inflammatory effects of Thd depend on AMPK signaling. However, further studies are required to demonstrate the mechanisms of Thd in the AMPK signaling pathway.

In conclusion, the current study is the first in vitro study to demonstrate that Thd reduces inflammation via the activation of AMPK, and the inhibition of the NF- $\mathrm{\kappa B} / \mathrm{MCP}-1$ signaling pathway in HG-induced MCs, to the best of our knowledge. These results suggest that Thd may have therapeutic potential in diabetic renal injury. However, further studies are required to elucidate the molecular mechanism underlying Thd-induced AMPK activation in DN.

\section{Acknowledgements}

Not applicable.

\section{Funding}

The present study was supported by the Basic Research Project of Shanxi Province (grant no. 201701D111001).

\section{Availability of data and materials}

All data generated or analyzed during this study are included in this published article. 


\section{Authors' contributions}

HXZ and RSL designed the study and provided research funding. JY and YFL designed the experiments and provided technical guidance. HXZ and JY performed the experiments. HXZ and JY wrote the manuscript. All authors read and approved the final manuscript.

\section{Ethics approval and consent to participate}

Not applicable.

\section{Patient consent for publication}

Not applicable.

\section{Competing interests}

The authors declare that they have no competing interests.

\section{References}

1. International Diabetes Federation: IDF Diabetes Atlas 7th edition (2015). https://www.idf.org/e-library/epidemiology-research/ diabetes-atlas/13-diabetes-atlas-seventh-edition.html. Accessed August 14, 2018.

2. Kolset SO, Reinholt FP and Jenssen T: Diabetic nephropathy and extracellular matrix. J Histochem Cytochem 60: 976-986, 2012.

3. Mason RM and Wahab NA: Extracellular matrix metabolism in diabetic nephropathy. J Am Soc Nephrol 14: 1358-1373, 2003.

4. Wada $J$ and Makino H: Inflammation and the pathogenesis of diabetic nephropathy. Clin Sci (Lond) 124: 139-152, 2013.

5. Navarro-González JF, Mora-Fernández C, Morus de Fuentes M and García-Pérez J: Inflammatory molecules and pathways in the pathogenesis of diabetic nephropathy. Nat Rev Nephrol 7: 327-340, 2011.

6. Min D, Lyons JG, Bonner J, Twigg SM, Yue DK and McLennan SV: Mesangial cell-derived factors alter monocyte activation and function through inflammatory pathways: Possible pathogenic role in diabetic nephropathy. Am J Physiol Renal Physiol 297: F1229-F1237, 2009.

7. Ingaramo PI, Ronco MT, Francés DE, Monti JA, Pisani GB, Ceballos MP, Galleano M, Carrillo MC and Carnovale CE: Tumor necrosis factor alpha pathways develops liver apoptosis in type 1 diabetes Mellitus. Mol Immunol 48: 1397-1407, 2011.

8. Giunti S, Tesch GH, Pinach S, Burt DJ, Cooper ME, Cavallo-Perin P, Camussi G and Gruden G: Monocyte chemoattractant protein-1 has prosclerotic effects both in a mouse model of experimental diabetes and in vitro in human mesangial cells Diabetologia 51: 198-207, 2008.

9. Kemp BE, Stapleton D, Campbell DJ, Chen ZP, Murthy S, Walter M, Gupta A, Adams JJ, Katsis F, van Denderen B, et al: AMP-activated protein kinase, super metabolic regulator. Biochem Soc Trans 31: 162-168, 2003.

10. Decleves AE, Mathew AV, Cunard R and Sharma K: AMPK mediates the initiation of kidney disease induced by a high-fat diet. J Am Soc Nephrol 22: 1846-1855, 2011.

11. Hallows KR, Mount PF, Pastor-Soler NM and Power DA: Role of the energy sensor AMP-activated protein kinase in renal physiology and disease. Am JPhysiol Renal Physiol 298: F1067-F1077, 2010.

12. Lv ZM, Liu Y, Zhang PJ, Xu J, Jia ZH, Wang R and Wan Q: The role of AMPK $\alpha$ in high glucose-induced dysfunction of cultured rat mesangial cells. Ren Fail 34: 616-621, 2012.

13. Wang S, Zhang M, Liang B, Xu J, Xie Z, Liu C, Viollet B, Yan D and Zou MH: AMPKalpha2 deletion causes aberrant expression and activation of NAD $(\mathrm{P}) \mathrm{H}$ oxidase and consequent endothelial dysfunction in vivo: Role of $26 \mathrm{~S}$ proteasomes. Circ Res 106: 1117-1128, 2010.
14. Kim MY, Lim JH, Youn HH, Hong YA, Yang KS, Park HS, Chung S, Ko SH, Shin SJ, Choi BS, et al: Resveratrol prevents renal lipotoxicity and inhibits mesangial cell glucotoxicity in a manner dependent on the AMPK-Sirt1-PGCl $\alpha$ axis in $\mathrm{db} / \mathrm{db}$ mice. Diabetologia 56: 204-217, 2013.

15. Salminen A, Hyttinen JM and Kaarniranta K: AMP-activated protein kinase inhibits $\mathrm{NF}-\kappa \mathrm{B}$ signaling and inflammation: Impact on healthspan and lifespan. J Mol Med (Berl) 89: 667-676, 2011.

16. Lee JH, Kim JH, Kim JS, Chang JW, Kim SB, Park JS and Lee SK: AMP-activated protein kinase inhibits TGF- $\beta-$, angiotensin II-, aldosterone, high glucose-, and albumin-induced epithelial-mesenchymal transition. Am J Physiol Renal Physiol 304: F686-F697, 2013.

17. Raje N and Anderson K: Thalidomide - a revival story. N Engl J Med 341: 1606-1609, 1999.

18. Asher $C$ and Furnish T: Lenalidomide and thalidomide in the treatment of chronic pain. Expert Opin Drug Saf 12: 367-374, 2013.

19. Amirshahrokhi $\mathrm{K}$ and Ghazi-Khansari M: Thalidomide attenuates multiple low-dose streptozotocin-induced diabetes in mice by inhibition of proinflammatory cytokines. Cytokine 60: 522-527, 2012.

20. Zhao J, Wang H, Song T, Yang Y, Gu K, Ma P, Zhang Z, Shen L, Liu J and Wang W: Thalidomide promotes morphine efficacy and prevents morphine-induced tolerance in rats with diabetic neuropathy. Neurochem Res 41: 3171-3180, 2016.

21. Behl T, Kaur I, Goel H and Kotwani A: Significance of the antiangiogenic mechanisms of thalidomide in the therapy of diabetic retinopathy. Vascul Pharmacol 92: 6-15, 2017.

22. Kim DH, Kim YJ, Chang SA, Lee HW, Kim HN, Kim HK, Chang HJ, Sohn DW and Park YB: The protective effect of thalidomide on left ventricular function in a rat model of diabetic cardiomyopathy. Eur J Heart Fail 12: 1051-1060, 2010.

23. Zhang H, Yang Y, Wang Y, Wang B and Li R: Renal-protective effect of thalidomide in streptozotocin-induced diabetic rats through anti-inflammatory pathway. Drug Des Devel Ther 12: 89-98, 2018.

24. Xu WW, Guan MP, Zheng ZJ, Gao F, Zeng YM, Qin Y and Xue YM: Exendin-4 alleviateshigh glucose-induced rat mesangial cell dysfunction throughthe AMPK pathway. Cell Physiol Biochem 33: 423-432, 2014.

25. García-García PM, Getino-Melián MA, Domínguez-Pimentel V and Navarro-González JF: Inflammation in diabetic kidney disease. World J Diabetes 5: 431-443, 2014.

26. Williams MD and Nadler JL: Inflammatory mechanisms of diabetic complications. Curr Diab Rep 7: 242-248, 2007.

27. Tesch GH: MCP-1/CCL2: A new diagnostic marker and therapeutic target for progressive renal injury in diabetic nephropathy. Am J Physiol Renal Physiol 294: F697-F701, 2008.

28. Morii T, Fujita H, Narita T, Shimotomai T, Fujishima H, Yoshioka N, Imai H, Kakei M and Ito S: Association of monocyte chemoattractant protein-1 with renal tubular damage in diabetic nephropathy. J Diabetes Complications 17: 11-15, 2003.

29. Cheng J, Diaz Encarnacion MM, Warner GM, Gray CE, Nath KA and Grande JP: TGF-betal stimulates monocyte chemoattractant protein-1 expression in mesangial cells through a phosphodiesterase isoenzyme 4-dependent process. Am J Physiol Cell Physiol 289: C959-C970, 2005.

30. Lee MJ, Feliers D, Mariappan MM, Sataranatarajan K, Mahimainathan L, Musi N, Foretz M, Viollet B, Weinberg JM, Choudhury GG and Kasinath BS: A role for AMP-activated protein kinase in diabetes-induced renal hypertrophy. Am J Physiol Renal Physiol 292: F617-F627, 2007.

31. Zhao J, Miyamoto S, You YH and Sharma K: AMP-activated protein kinase (AMPK) activation inhibits nuclear translocation of Smad4 in mesangial cells and diabetic kidneys. Am J Physiol Renal Physiol 308: F1167-F1177, 2015.

32. Dugan LL, You YH, Ali SS, Diamond-Stanic M, Miyamoto S, DeCleves AE, Andreyev A, Quach T, Ly S, Shekhtman G, et al: AMPK dysregulation promotes diabetes-related reduction of superoxide and mitochondrial function. J Clin Invest 123: 4888-4899, 2013. 